\title{
Research and Suggestions on the Present Situation of Shared Bicycle Parking Spot on University Campus
}

\author{
Lijuan Zhu1,a, Hong Xu1,2, Yan Long ${ }^{1,2}$, Junying Luo ${ }^{1}$, Yujie Chen ${ }^{1}$, Xia Yang ${ }^{1}$ \\ ${ }^{1}$ School of Urban Construction, Wuhan University of Science and Technology, Wuhan 430065, China \\ ${ }^{2}$ Institute of Smart City and Intelligent Urban-rural development, Wuhan University of Science and Technology, Wuhan 430065, China
}

\begin{abstract}
As an important means of short-distance travel for college students, sharing bicycle parking and planning is particularly noteworthy. This requires not only considering the layout of buildings and environment on campus, but also systematically improving and designing with the combination of behavior characteristics and human factors. Based on the research and analysis of the current situation of sharing bicycles among college students, this paper puts forward some suggestions for improving the design of parking spaces in College campuses.
\end{abstract}

\section{Research background}

\subsection{Background and current situation of college students sharing bicycle use}

In response to the civilized city and the green slogan, many first- and second-tier cities in China have actively promoted walking and bicycle green travel, achieving the environmental protection goal of energy conservation and emission reduction. ${ }^{1}$ With the development of sharing bicycles and shared bicycles in recent years, the concept of bicycle green travel has become more and more popular among the people. Especially in the university campus, sharing bicycles has received the welcome and support of teachers and students. ${ }^{2}$ As a provincial university, Wuhan University of Science and Technology has a large school area. Teachers and students mainly use bicycles. The emergence of shared bicycles not only solves the problem of travel efficiency, but also improves the efficiency of bicycle use. Compared with private bicycles, shared bicycles. ${ }^{3}$ Greatly reduced the cost of the people. The increasing number of shared bicycles has brought about the parking problem. The parking characteristics of shared bicycles are discretely distributed. The characteristics of free parking have brought challenges to the city's public management order.

For university campuses that are vigorously developing bicycle green transportation, high-utility, low-cost shared bicycles are the best choice for teachers and students. Providing a continuous, safe and comfortable passage for shared bicycles, as part of the university campus culture, sharing bicycle parking facilities represents not only a public facility, but also the spiritual and cultural connotation of a university campus. Take Wuhan University of Science and Technology as an example. At present, the planning and construction of shared bicycle public parking facilities will not meet the needs of the future. How to combine the land layout and travel needs of university campuses, share the shared parking lot, and combine the environment with teachers and students. Behavioral characteristics Reasonable design of on-site parking facilities, so that they are perfectly integrated with the campus, has become a major problem that the current school management department needs to solve. ${ }^{6}$ In summary, at this stage, the research on the status quo of the use of shared bicycles and the study of the usage rules and characteristics have important theoretical and practical significance, and finally provide guidance for the planning, layout and construction management of parking facilities for shared bicycles.

\subsection{Research at home and abroad}

Since the 1970s, attention has been paid to the construction and use of bicycles. ${ }^{4}$ Since the beginning of the 21 st century, research on public bicycles has been carried out. European countries have carried out a series of studies on the impact of bicycle construction on transportation. While there are certain considerations in terms of people's choices and travel behaviors, more attention is paid to the construction, operation and use characteristics of bicycles. ${ }^{5}$ The government will also exercise some powers to focus on the use of bicycles and parking facilities. ${ }^{6}$

In foreign countries, each country has taken different measures to solve the problem of bicycle parking. In Japan, the parking facilities of bicycles have also been planned accordingly, and comprehensive research has been carried out in terms of their public environment and underground passages. In addition, there are also Denmark, the Netherlands and Germany. ${ }^{7}$ These countries have bicycle lanes for travel, integrated design of public

a Lijuan Zhu:2678353611@qq.com 
transport and bicycle traffic, and fully equipped bicycle parking facilities to make bicycles and motor vehicles in the urban transportation system. Some equally important positions. $^{8}$

Today, there are two main forms of bicycle parking in China. One is flat parking, sub-card type and spiral type. The other is a multi-layer parking form. On the basis of plane parking, through the transformation of the double-layer bicycle parking rack, the three-dimensional space can be fully utilized to automatically and intelligently park the bicycle, and the space resources can be maximized while being more beautiful. Use, provide more bicycle parking spaces.

\subsection{Research purposes and significance}

The planning and layout of parking facilities for shared bicycles on university campuses is very important. First of all, it is particularly prominent during the peak period of class. The class and the class flow are concentrated at the same time. The parking facilities on the roads with large traffic flow will seriously affect traffic. Secondly, due to the short time between classes, the students have limited time and there is not enough time to park the vehicles as required. As a result, the shared bicycles are parked and unloaded, which causes the already congested traffic to deteriorate and easily lead to safety accidents. Once again, the disorderly placement of shared bicycles and the messy parking lot will become a stain on the beautiful university campus. Therefore, from the perspective of the unified planning and layout of the university campus, we think about the parking, transportation, safety and landscape of shared bicycles, and propose a design method that combines bicycle parking with the dimensions of architecture, transportation, landscape and human behavior. Starting from the parking problem of bicycles on university campuses, using on-site surveys, questionnaires, field interviews, etc., taking the design of shared bicycle planning and parking facilities on the campus of Wuhan University of Science and Technology as an example, in order to solve the current problem of shared bicycle parking in colleges and universities. Disorders and other issues, and restore and improve the campus environment, so that shared bicycles can be better utilized in the university campus.

\section{Current situation research}

This study uses GPS to track the shared bicycles in various areas of Wuhan University of Science and Technology. It has accurately grasped the distribution of shared bicycles in various regions and time periods in the school. On the selection of time samples, through the GPS positioning of the shared bicycles on the campus of Wuhan University of Science and Technology, it was found that the usage rate of shared bicycles in the four seasons of the year was significantly different in different seasons. lowest. In order to eliminate the interference of the seasons on the shared bicycle usage rate, consider the higher usage rate, and select the data with milder weather in the spring for data analysis.

\subsection{Analysis of the present situation of shared bicycle parking spots}

Through the survey, the distribution of shared bicycle parking spots on the campus of Wuhan University of Science and Technology was obtained, and the floor plan was drawn and divided into different areas. (Table 1)

Table 1. Campus partition.

\begin{tabular}{|l|l|}
\hline $\begin{array}{l}\text { Dormitory living } \\
\text { area }\end{array}$ & $\begin{array}{l}\text { Including: North Park Dormitory (North } \\
\text { 1-15), South Park Dormitory (South 1-13), } \\
\text { faculty dormitory, North and South Garden } \\
\text { canteen }\end{array}$ \\
\hline $\begin{array}{l}\text { Teaching office } \\
\text { area }\end{array}$ & $\begin{array}{l}\text { Including: (Teach the first floor - teach the } \\
\text { sixth floor, Yifu Building, library, } \\
\text { engineering training center) }\end{array}$ \\
\hline $\begin{array}{l}\text { Sports and } \\
\text { recreation area }\end{array}$ & $\begin{array}{l}\text { Including: North and South Park Stadium, } \\
\text { North Park Gymnasium, North and South } \\
\text { Garden Restaurant, Qin lake and a series of } \\
\text { nearby areas for students to entertain }\end{array}$ \\
\hline $\begin{array}{l}\text { School entrance } \\
\text { and exit and its } \\
\text { vicinity }\end{array}$ & $\begin{array}{l}\text { Including: various entrances and exits of } \\
\text { the school and areas within the school }\end{array}$ \\
\hline other & $\begin{array}{l}\text { Including: on-campus driving school, } \\
\text { on-campus research center, and areas where } \\
\text { people are not constantly moving }\end{array}$ \\
\hline
\end{tabular}

From 6 o'clock, every three hours is a time node, and the shared bicycle positioning and investigation at various locations in the school, through GIS technology statistics and analysis, the distribution of the number of shared bicycles in different regions of the school is obtained .( Table 2) At the same time, analyze and determine important shared bicycle parking spots.

Table 2. Space-time distribution of shared bicycles.

\begin{tabular}{|c|c|c|c|c|c|}
\hline $\begin{array}{c}\text { Time/ } \\
\text { partition }\end{array}$ & $\begin{array}{c}\text { Dormitory } \\
\text { living area }\end{array}$ & $\begin{array}{c}\text { Teaching } \\
\text { area }\end{array}$ & $\begin{array}{c}\text { Recreation } \\
\text { area }\end{array}$ & $\begin{array}{c}\text { School } \\
\text { entrance } \\
\text { and exit }\end{array}$ & Other \\
\hline 6 & $45 \%$ & $18 \%$ & $8 \%$ & $10 \%$ & $19 \%$ \\
\hline 9 & $25 \%$ & $32 \%$ & $9 \%$ & $15 \%$ & $19 \%$ \\
\hline 12 & $43 \%$ & $24 \%$ & $5 \%$ & $8 \%$ & $20 \%$ \\
\hline 15 & $32 \%$ & $27 \%$ & $5 \%$ & $7 \%$ & $19 \%$ \\
\hline 18 & $39 \%$ & $12 \%$ & $5 \%$ & $26 \%$ & $18 \%$ \\
\hline 21 & $47 \%$ & $13 \%$ & $7 \%$ & $15 \%$ & $18 \%$ \\
\hline
\end{tabular}

\subsection{Factors affecting shared bicycle parking}

The survey found that the parking location of shared bicycles on campus will be greatly affected by time. This phenomenon is mainly related to the daily behavior of college students.

The North and South Court dormitory living area is divided into dining area and dormitory area, according to the specific location of the school entrance and exit and its vicinity divided into four pieces, choose a mild winter weather day record shared cycle data, specific analysis of the impact of time in each region on the use and parking of shared bicycles. (Table 3 and 4) 
Table 3: It is found that the number of shared bicycles in the North dining area and dormitory area is greatly affected by time. This phenomenon is consistent with the daily behavior of college students. The number of shared bicycles in the South dormitory area is also affected by time, but different from the North. There are more student organizations in the South dormitory area, which causes other peaks in the number of shared bicycles. The number of shared bicycles in the South dining area is less affected by time, mainly because the canteen staff staying near the South dining area occupy a large number of shared bicycles. Secondly, more South students will choose to eat at the commercial street near the campus.

Table 3. Number of shared bicycle parking in the living area.

\begin{tabular}{|c|c|c|c|c|}
\hline $\begin{array}{c}\text { Time/ } \\
\text { partition }\end{array}$ & $\begin{array}{c}\text { The North } \\
\text { living area }\end{array}$ & $\begin{array}{c}\text { The South } \\
\text { living area }\end{array}$ & $\begin{array}{c}\text { The North } \\
\text { dining area }\end{array}$ & $\begin{array}{c}\text { The South } \\
\text { dining area }\end{array}$ \\
\hline 6 & 4 & 13 & 10 & 5 \\
\hline 9 & 3 & 3 & 12 & 2 \\
\hline 12 & 5 & 4 & 10 & 4 \\
\hline 15 & 0 & 4 & 11 & 6 \\
\hline 18 & 3 & 4 & 10 & 9 \\
\hline 21 & 1 & 14 & 7 & 8 \\
\hline 24 & 1 & 17 & 8 & 4 \\
\hline
\end{tabular}

Table 4 finds that the number of shared bicycles in the teaching office area and the number of shared bicycles in the South dormitory living area have changed inversely with time, which is closely related to the daily behavior of college students. The number of shared bicycles in the South dormitory living area has not fluctuated with time, which is due to the South. The dormitory living area has a strong comprehensive function.

Table 4. Comparison of the number of shared bicycles between the teaching area and the dormitory living area.

\begin{tabular}{|c|c|c|c|}
\hline Time/partition & Teaching area & South & South \\
\hline 6 & 20 & 17 & 15 \\
\hline 9 & 35 & 6 & 14 \\
\hline 12 & 27 & 9 & 14 \\
\hline 15 & 25 & 4 & 17 \\
\hline 18 & 13 & 7 & 19 \\
\hline 21 & 11 & 15 & 15 \\
\hline 24 & 14 & 18 & 12 \\
\hline
\end{tabular}

\subsection{Problem analysis}

\subsubsection{Unreasonable layout}

When sharing bicycles are used on campus, the range of parking facilities should be fixed. A survey of shared bicycles during each time period found that nearly $75 \%$ of vehicles were parked in the main functional area of the campus. About $25 \%$ of the vehicles were parked in more remote locations, and users were more difficult to find and use during regular travel, limiting the efficiency of the use of shared bicycles. Most of the vehicles on the campus are also distributed in the main functional areas such as the teaching area and the living area. Therefore, it is important to plan the areas where the bicycle parking facilities are shared in these two areas. This will help reduce the time for users to find cars and also make the vehicles of the school. The parking arrangement is more reasonable and easy to arrange and manage.

\subsubsection{Design is not standardized}

Many parking spots are not well-designed, some are blocked by motor vehicles, there is no reasonable connection with the road or lack of canopy. These reasons will make teachers and students discouraged, resulting in low parking space usage. (Figure 1,2 and 3)

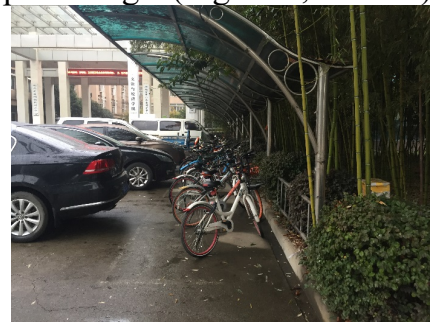

Figure 1. Shared bicycle parking spot blocked by motor vehicles.

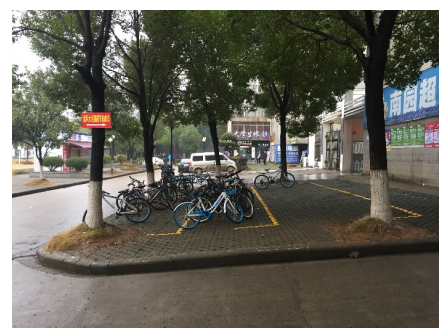

Figure 2. Shared bicycle parking spot without shelter.

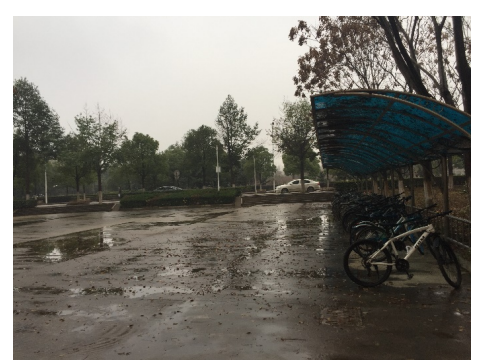

Figure 3. Need to climb the stairs to reach the shared bicycle parking spot.

\subsubsection{Smaller scale}

The parking area painted with yellow paint on the campus is obviously too small, and the form is extremely simple, with no new ideas and features. The narrow aisle severely restricts people's access to shared bicycles, affects the normal traffic of pedestrians, and often causes a "domino" type of reversing accident.

\subsubsection{Poor environment}

Due to the characteristics of shared bicycle free parking, in addition to some specific areas planned to have "shared bicycle recommended parking spots", shared bicycles are mainly mixed with ordinary non-motor vehicles. At 
present, the construction management of non-motor vehicle parking facilities in China has not received much attention, and there is no design at all. Designers of shared bicycle parking facilities should not only consider the number, but also ensure that parking facilities are parked as much as possible, and there is no lack of aesthetic considerations. ${ }^{9}$ (Figure 4 )

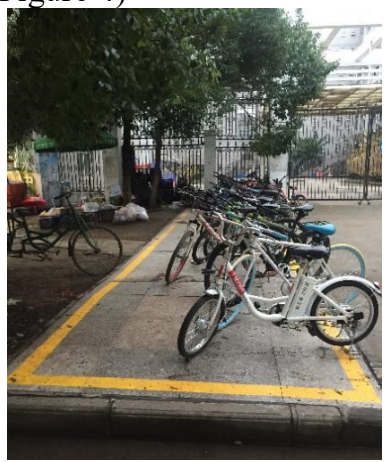

Figure 4. Use a line to draw a small shared bike parking spot.

\section{Optimization strategy}

\subsection{Reasonable layout of bicycle parking spots}

For the planning and layout of parking facilities, the location of parking facilities should give priority to its convenience, and make reasonable planning and effective layout without affecting campus traffic. ${ }^{10}$ The location of the bicycle public parking point should be combined with the development of the land parcel. It should be set at the convenient and awake destination and close to the pedestrian entrance and exit. It should be $30 \sim 40 \mathrm{~m}$ away from the pedestrian entrance and exit; the construction scale of the building, canteen and other types of buildings is generally large. Moreover, the parking demand is large. It is recommended to set up a centralized bicycle parking lot in combination with the development of the plot to facilitate management; the inner/road side of the campus trunk road can meet the parking demand through decentralized parking spots.

\subsection{Standard design of facilities in the parking lot}

\subsubsection{Paving}

The layout of the shared bicycle parking facilities should be smooth, solid and non-slip. It can be paved with permeable bricks and other greening facilities. For example, you can use grass bricks to make pavements, which can reduce the area of hard paving. To increase the green area of the campus and reduce the thermal effects caused by the parking lot. ${ }^{11}$ Combine the landscape ecological environment with the parking space to improve the interior landscape and space environment of the university campus.

\subsubsection{Occlusion}

For long-term parking, especially overnight parking, such as bedroom buildings, teaching buildings, school gates, etc., should be equipped with a canopy to improve the parking environment of bicycles. At the same time, the carport is required to have better light to meet the needs of the storage vehicle.

\subsubsection{Signs and lines}

In addition to the range of permanent parking facilities, semi-permanent and temporary parking facilities should be set and marked with signs and markings, and the corresponding parking rules should be announced to facilitate the use of the parking lot and the implementation of campus management.

\subsection{Greening}

Planting suitable trees in or around the parking lot should be carried out without affecting the passage and parking of the vehicles. ${ }^{12}$ The advantage of this setting is that not only can it have a good landscape effect, but also protect the campus environment. A large number of shades can block the sun in the summer, and the winter does not affect the penetration of the sun, which can effectively protect the vehicle. However, the planting of the trees does not obscure the back of the building. It is best to plant it on the side of the gable of the building or on the same side of the gable as the road. Of course, attaching certain green and architectural pieces can play a finishing touch.

\subsection{Diversified functions and optimized environment}

Considering the limitation of the width of the green belt in the design, the oblique parking mode is often adopted. The advantage of this method is that it is convenient to park and can effectively utilize non-passage space resources.

(1) Design of parking spots: through the perspective of the landscape.

A canopy and frame with a beautiful appearance and a unique shape are set at a fixed shared bicycle parking spot. At the same time, the landscape design of the canopy, design unique shapes and select the appropriate color, while paying attention to the relationship between body size and volume, so that the parking facilities not only have the protection of sun and rain, but also reflect the elegant and beautiful design aesthetics. It highlights the charm of the campus.

(2) Greening and architectural sketches

The shared bicycle parking facility can be combined with flowers, trees, water bodies, sculptures, etc. to create landscape pieces that meet regional characteristics, which is beneficial to the effective use of natural space resources and the creation of a unique campus street environment. At the same time, it is convenient for students to park, and can design eye-catching reminding facilities, placed next to the parking facilities, should be based on the size, color 
and space saving, according to the requirements of design and display of signs, markings, signs.

\section{Summary}

The shared bicycle parking spots on university campuses as part of the campus street landscape, the problems they face should be properly resolved, not blindly avoided. The design and modification of shared bicycle parking spots not only solves the hardware problems of site layout and facility design, but also solves the software problem of "parking chaos" phenomenon. ${ }^{13}$ On the university campus, the existing shared bicycle parking facilities should be relocated, planned, designed and managed to improve the static traffic of campus bicycles, and create a safe, reliable, comfortable, convenient, quiet and harmonious bicycle parking environment for college students.

\section{Acknowledgments}

This research was financially supported by the National College Students' innovation and entrepreneurship training program project of China (201710488016).

\section{References}

1. Yujia Huang, Zhongliang Yang, Shuhua Xiong. The research on the control algorithm of iot based bicycle parking system [C], IEEE Beijing section: Institute of Electrical and Electronics Engineers, Inc., 2012: 1734-1738.

2. Junbin $\mathrm{Xu}$, Zhiyong Zhang, Jian Rong. The Forecasting Model of Bicycle Parking Demand on Campus Teaching and Office District [J]. Procedia Social and Behavioral Sciences, 2012, 43: 550-557.

3. Changzheng Yuan, Yangbo Sun, Jun Lv. Cycle Tracks and Parking Environments in China: Learning from College Students at Peking University [J]. MDPI, 2017, 14(8):
4. Jingxu Chen, Zhibin Li, Hang Jiang. Simulating the impacts of on-street vehicle parking on traffic operations on urban streets using cellular automation [J]. Physica A: Statistical Mechanics and its Applications, 2017, 468 (Missing period): 880-891.

5. David a. Moskovitz, Nikki Wheeler. Bicycle Parking Analysis with Time Series Photography [J]. SAGE Publications, 2011, 2247(1): 64-71.

6. Eric Molin, Kees Maat. Bicycle parking demand at railway stations: Capturing price-walking tradeoffs [J]. Research in Transportation Economics, 2015, 53: 3-12.

7. Paul Christian Pfaffenbichler, Tadej Brezina. Estimating bicycle parking demand with limited data availability [J]. Thomas Telford Ltd, 2016, 169(2): 76-84.

8. Elizabeth Flanagan, Ugo Lachapelle, Ahmed el-geneidy. Riding tandem: Does cycling infrastructure investment mirror gentrification and privilege in Portland, OR and Chicago, IL[J]. Research in Transportation Economics, 2016, Volume missing (Missing period):

9. Peng Chen, Qian Liu, Feiyang Sun. Bicycle parking security and built environments $[\mathrm{J}]$. Elsevier India Pvt Ltd., 2018, 62: 169-178.

10. Hong-yi Chang, Shih-chang Huang, Yuan-wei Lin. An efficient cloud-assisted best-parking algorithm for BikeNet [J]. Inderscience Publishers, 2014, 16(2): 136-148.

11. Zhang Jianmin, Zhou Jun, Liu Lei. Suspension Type Stereo Bicycle Parking Garage [J]. American Journal of Applied Scientific Research, 2016, 2(6).

12. Stefan Christiaan van der spek, Noor Scheltema. The importance of bicycle parking management [J]. Research in Transportation Business \&amp; Management, 2015, 15: 39-49.

13. David Arbis, Taha Hossein Rashidi, Vinayak V. Dixit. Analysis and planning of bicycle parking for public transport stations $[\mathrm{J}]$. International Journal of Sustainable Transportation, 2016, 10(6): 495-504. 